\title{
Marzolph, Ulrich (2020): 101 Middle Eastern Tales and Their Impact on Western Oral Tradition, Detroit, Wayne State University Press, 706 pp.
}

Los cuentos son muestras vivas de la identidad de una colectividad, de su pasado y su presente; registros de lo que fue y de lo que es hoy; forman parte intrínseca de su patrimonio cultural, literario, folclórico y antropológico - ya sea a nivel local, regional, nacional o supranacional - y uno de los rasgos en los que se reconoce como grupo. La contribución de las narrativas orientales desde la Edad Media a la configuración de las europeas suscitó un debate - muchas veces centrado en la magnitud de tal aportaciónya superado en la academia a partir de los estudios científicos y repertorios que han esclarecido los vínculos y los precedentes orientales de cientos de relatos de la literatura y del folclore de Occidente. Pero no solo se trata de tener en cuenta, estudiar y ahondar en ese vínculo desde la esfera académica — donde se sigue trabajando en ello-, sino de lograr que la sociedad identifique a las culturas orientales - empleando la terminología que se usa en el libro - como parte fundamental de la identidad colectiva de Occidente, y que aprecie y valore su patrimonio común en forma de cuentos. Pues bien, la obra que reseñamos constituye una contribución a todo ello, no tan modesta como su autor señala en sus primeras páginas (p. 3), según se expondrá.

En 101 Middle Eastern Tales and Their Impact on Western Oral Tradition, Ulrich Marzolph analiza un muestrario de 101 cuentos transmitidos a Occidente desde o a partir de las literaturas árabe, persa y turca otomana y cuya huella se advierte en las tradiciones orales de Europa y el continente americano entre los siglos XIX y XX, dando a conocer sus orígenes, sus manifestaciones y difusión, sus peculiaridades y sus relaciones con otros cuentos. Se trata de relatos arraigados en la tradición oral moderna occidental — de calado igualmente en la tradición escrita desde la Edad Media - y que forman parte intrínseca de ella y de la identidad de las comunidades donde se han registrado. Como el propio autor explica al inicio de su introducción (pp. 2-3), los relatos incluidos en su obra se ajustan a dos parámetros fundamentales recién mencionados: a) su origen se encuentra en fuentes orientales o fueron transmitidos a partir de ellas; b) se trata de cuentos difundidos oralmente y documentados en la tradición oral de Occidente en el periodo temporal antes precisado. Se excluyen conscientemente los cuentos con antepasados en la Antigua Grecia y Roma, dada la probabilidad de que su penetración en la tradición occidental se produjera a partir de fuentes grecorromanas clásicas (pp. 2-3).

Dicho esto, el título del libro orienta sobre la que es motivación principal del autor: dar a conocer y subrayar el impacto que estos cuentos procedentes de las narrativas orientales ejercieron en la tradición oral occidental, tan prolongado en el tiempo que hace que hoy estemos ante relatos de gran arraigo en esta última (adaptados y adoptados por ella, como escribe Marzolph) y de un patrimonio compartido entre ambas.

Consciente de la ambigüedad de hablar de cuentos «orientales», el autor delimita en su introducción lo que es en el libro Middle East (Oriente), término con el que se abarca la región levantina del mundo árabe-islámico (Oriente Medio), los Balcanes, el norte de África y al-Andalus (p. 4). Además, como sucede cuando nos referimos a la tradición «occidental», es inevitable caer en una cierta homogeneización cultural y en 
cuanto a narrativas, por eso los términos «Oriente» y «oriental» aparecen siempre entre comillas.

Este libro llega casi treinta años después de que el propio Ulrich Marzolph, referente desde hace décadas en los estudios de la cultura narrativa del mundo islámico, publicara en 1992 Arabia Ridens, trabajo en dos volúmenes centrado en la prosa humorística breve en la literatura árabe clásica (fundamentalmente en el $a d a b$ ) en el que ya llamaba la atención sobre la riqueza en materiales narrativos de ese género - muchos de ellos folclóricos - y sobre las dimensiones del corpus compartido con la tradición europea, entre otras, aportando un extenso repertorio de cuentos enunciados con anotaciones sobre su presencia en aquellas literaturas y referencias al catálogo AT y a otros trabajos destacados en el campo. Me refiero a la Bibliographie des ouvrages arabes de Chauvin, los Mille et un contes de Basset o las antologías anotadas de Wesseslki, principales materializaciones académicas del estudio de los cuentos orientales y su conexión con la narrativa occidental, sin olvidar los primeros volúmenes de la Enzyklopadie des Märchens, donde ya se comenzaba a prestar atención a la narrativa del mundo islámico. Desde entonces, ha habido avances puntuales y aportaciones significativas, como estudios sobre cuentos concretos o la aparición de catálogos de cuentos folclóricos del mundo árabe, persa y turco, que han favorecido una mayor presencia de dichas tradiciones en el catálogo ATU y en otros de alcance más particular, pero no un trabajo de conjunto y de mayor envergadura como el presente. Uno de los méritos de este último es que aglutina referencias esparcidas en toda esta bibliografía precedente, y supone una ampliación de trabajos anteriores del autor y la actualización de la información relativa a los cuentos examinados con los estudios y catálogos de cuentos folclóricos y populares más recientes.

El libro es fruto de años de concienzudo trabajo de recopilación sistemática de datos de las fuentes árabes, persas y turcas otomanas por parte del autor, y de un profundo conocimiento de la literatura y el folclore de Europa. Comienza con una concisa pero ilustrativa introducción (pp. 1-28), dividida en varios apartados en los que trata sobre la motivación y temática del libro, la metodología seguida y las fuentes exploradas, o hace una retrospectiva sobre el estudio de los cuentos orientales como parte de las investigaciones histórico-comparatistas de las narrativas folclóricas y un repaso por los principales repertorios occidentales que contienen cuentos orientales desde el s. XII, entre otras cuestiones. Esta introducción allana el camino al lector no familiarizado con el área de investigación para la comprensión tanto del contenido del libro como de la magnitud de la empresa llevada a cabo.

El cuerpo del libro lo conforman 101 capítulos protagonizados por sendos cuentos, todos ellos de carácter folclórico y sistematizados en la clasificación ATU, que se usa como referente organizativo. Así, los relatos están ordenados por tipos del folclore internacional, siguiendo la numeración establecida en dicho catálogo, en orden ascendente. Este principio de organización de tan enciclopédica información resulta el más útil y reconocible para el lector especialista, así como para el aficionado habituado a leer sobre temas de folclore. Para el público general es más esclarecedor, quizá, el título que se da a cada cuento, que encabeza cada ensayo antes de la numeración ATU y resulta más o menos revelador de su temática. Por lo general, estos títulos no se corresponden necesariamente con los consignados en el catálogo ATU. En cuanto a los cuentos estudiados, la mayoría (n. 35-99) es de naturaleza jocosa y pertenece a la categoría de «Anecdotes and Jokes», a la que responde el grueso de cuentos llegados desde Oriente a Occidente y tan extendidos en la literatura árabe clásica en la prosa de $a d a b$ como componentes fundamentales de unas obras destinadas a instruir y divertir. Dentro de ellos, los n. 97-99 son "Tall Tales". El resto, — siguiendo las etiquetas ATU — son cuentos de animales (n. 1-5), maravillosos 
(n. 6-16), religiosos (n. 17-23), cuentos novela o realistas (n. 24-33), cuentos del ogro estúpido (n. 34) y cuentos formulísticos (n. 100-101).

En cuanto a la anatomía interna de los capítulos, el autor sigue un orden sistemático en todos ellos (con alguna ligera variación en algunos), lo cual facilita la localización de la información al lector, quien termina interiorizándolo y puede dirigir su atención, si así lo desea, a un aspecto concreto. Cada capítulo constituye un ensayo independiente entretejidos todos por el hilo de la temática del libro - en el que, siguiendo un enfoque histórico-comparatista, se procede al estudio del cuento en cuestión partiendo de una versión recopilada en la tradición oral de Occidente, cuyo texto se reproduce. Con todo, no habría estado de más iniciar cada ensayo con un breve resumen argumental del cuento, que sirviera de primer referente a los lectores no especialistas que no identifiquen la numeración de los tipos con su contenido temático.

Tras esta carta de presentación, se mencionan las muestras orales recolectadas en distintas tradiciones occidentales y, a continuación, el autor se centra en la existencia histórica del relato, primero en las fuentes escritas de Occidente y luego de Oriente. En los párrafos dedicados a la vida del relato en Occidente, se parte de las versiones más antiguas para mencionar después las posibles vías de transmisión a la tradición oral. Es de destacar la atención que se presta a géneros populares como los chapbooks en Inglaterra y Europa central o a calendarios y almanaques en España. En cuanto a la parte de los ensayos centrada en la tradición oriental, comienza con las primeras muestras de los cuentos en la literatura árabe, persa y turca otomana y continúa con sus manifestaciones posteriores en esas mismas fuentes. Si el cuento existe en la Antigua Grecia e India, se menciona y a veces se ahonda en ello. Cada ensayo concluye con las notas, en las que se proporciona una completa bibliografía para una aproximación más profunda y especializada a cada cuento. En algunos ensayos, el lector encontrará, destacadas en negrita, referencias internas que remiten a otros ensayos dentro del libro y ponen en conexión unos cuentos con otros.

Así pues, el libro constituye un valioso complemento actualizado al catálogo ATU, que refuerza y amplía la información contenida en esta obra de referencia sobre los cuentos con versiones en las literaturas árabe, persa y turca otomana. El hecho de estar redactado en inglés lo convierte, además, en una obra accesible a un público especializado mayor que Arabia Ridens, del mismo autor. Además, la manera en que está concebido le permite cumplir también con su propósito divulgativo, de forma que puede ser disfrutado por cualquier tipo de público interesado en la materia.

Sin duda estamos ante una de las aportaciones más valiosas al campo del folclore y la literatura comparada de los últimos tiempos en forma de manual, y ante un trabajo fundamental para corroborar el papel crucial de las narrativas orientales, especialmente la árabe y los relatos de la prosa de adab, en la configuración de la tradición occidental escrita y oral, cuya mayor aportación se reconoce en las narraciones folclóricas de tipo humorístico.

En definitiva, los estudios de narrativa y folclore están de enhorabuena con la publicación de esta importante contribución que está llamada a convertirse en uno de los catálogos de referencia en el ámbito.

Desirée López Bernal

Universidad de Granada

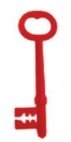

